\title{
A CASE OF PHAEOCHROMOCYTOMA IN CHILDHOOD
}

\author{
BY \\ M. ISRAELSKI, A. C. KENDAL L and R. E. SHAW \\ From the George Eliot Hospital, Nuneaton
}

(RECEIVED FOR PUBLICATION AUGUST 15, 1953)

A sufficient number of cases of phaeochromocytoma have now been described for the clinical features they present to be clearly defined. Once the diagnosis has been suspected, other conditions associated with hypertension in childhood can usually be excluded on clinical grounds. Confirmation may then be sought by means of the benzodioxane test (Goldenberg, Snyder and Aranow, 1947) and the more recently described assay of noradrenaline in the urine (von Euler, 1951). Operative treatment is aided considerably by pre-operative localization of the tumour, using the technique of extra-peritoneal pneumography, a method of investigation which appears to be free from the dangers associated with perirenal air insufflation. Lastly, the hazards associated with the operation itself can be reduced considerably by the use of benzodioxane. These means were used successfully in the case to be described.

\section{Case Report}

A boy aged 10 years presented with a nine months' history of loss of weight, $5 \mathrm{lb}$. being lost in the last six months, listlessness, excessive sweating, particularly at night and after exertion, increasing thirst and polyuria. For one month he had complained of frontal headaches which were worse on rising and he had vomited on three occasions. His mother's anxiety was increased by the fact that the boy's father had died at the age of 23 years after an illness presenting similar features. He had, she related, from the age of 16 years sweated excessively, but until six months tefore his death seemed well. Some impairment of vision was then complained of, he was found to have slight papilloedema, a blood pressure of $210 / 170 \mathrm{~mm} . \mathrm{Hg}$, and albumin, red cells and cellular casts were present in the urine. His death was apparently due to a cerebral catastrophe, but no necropsy was done.

The patient was normally proportioned for his age, although rather thin (height, 55 in., weight, $68 \frac{1}{2} \mathrm{lb}$.). Puberty changes had not begun. He had a pale face, an anxious expression and manner, his skin was moist and there were beads of sweat on his forehead. Over the hands and wrists there was a dull red flush, the upper limit of this change showing a sharp line of demarcation. Similar but less marked changes were present in the feet and ankles. The heart was not enlarged, the heart sounds were normal apart from an accentuated second sound in the aortic area, and there were no murmurs. His blood pressure was $200 \mathrm{~mm}$. systolic and $150 \mathrm{~mm}$. diastolic. Both fundi showed early papilloedema and an exudate in the form of a macular fan. There were no other abnormal findings.

Following admission to the ward his pulse rate was found to vary between 80 and 120 per minute but was mostly in the range of 80 to 100 . His skin was always moist and invariably during sleep sweating was profuse. The blood pressure showed marked spontaneous variation, the highest reading obtained being $250 \mathrm{~mm}$. systolic and $180 \mathrm{~mm}$. diastolic and at that time he perspired profusely and complained of severe frontal headache. His fluid intake varied from 3 to 5 pints a day.

Special Investigations.-Several specimens of urine were normal. A concentration test gave a specific gravity of 1020 . Urea clearance in the first hour was $96 \%$, and in the second $73 \%$. The blood urea level was $42 \mathrm{mg}$. per $100 \mathrm{ml}$. Analysis of the plasma proteins gave albumin $4 \cdot 6 \mathrm{~g}$. per $100 \mathrm{ml}$., globulin $2 \cdot 2 \mathrm{~g}$. per $100 \mathrm{ml}$.

A radiograph of the chest showed a normal cardiac outline.

Benzodioxane Test.-An intravenous drip of normal saline was started, and blood pressure readings were taken at minute intervals. Spontaneous fluctuations were seen (Fig. 1), but by the end of the seventh minute when stabilization seemed to be occurring, a visitor came and announced to the boy that his vicar had called to see him. There was an immediate rise in the systolic and diastolic pressures, and thereafter increased fluctuations about a generally higher level. When these fluctuations had diminished, $11 \mathrm{mg}$. of benzodioxane were injected over a period of two minutes. The systolic pressure immediately fell by $65 \mathrm{~mm}$., the diastolic pressure by $60 \mathrm{~mm}$., and this was followed by a steady rise, the pre-injection levels being reached by the end of 10 minutes.

Nor-Adrenaline Excretion.-This was at the rate of $2,000 \mu \mathrm{g}$. in 24 hours. The normal limits for a boy of this age are $10 \mu \mathrm{g}$. to $27 \mu \mathrm{g}$., average $20 \mu \mathrm{g}$.

Excretory Urogram.-There was good excretion from both kidneys. The right kidney shadow was somewhat larger than the left, and the upper pole of the right renal pelvis was slightly depressed (Fig. 2).

Extra-Peritoneal Pneumography.-This procedure was carried out according to the technique described by Blackwood (1951). Morphine, grain $\frac{1}{8}$, was given half an 


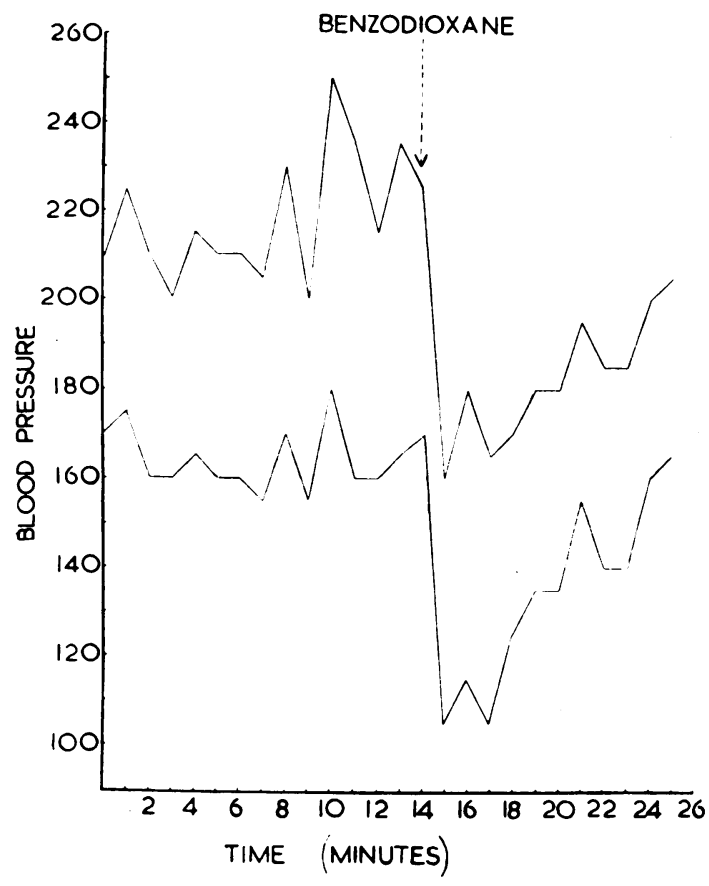

FiG. 1.-Results of benzodioxane test.

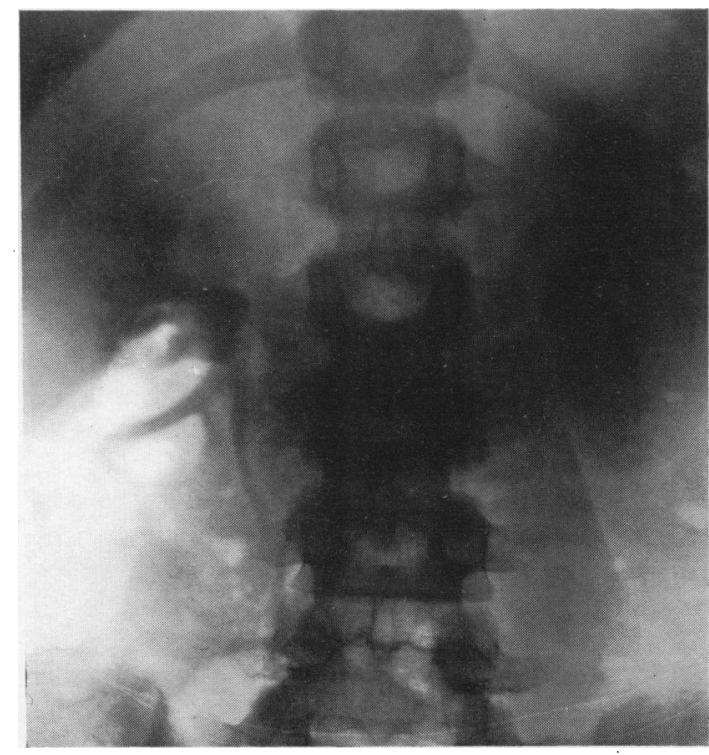

FIG. 2.-Urogram of excretion.

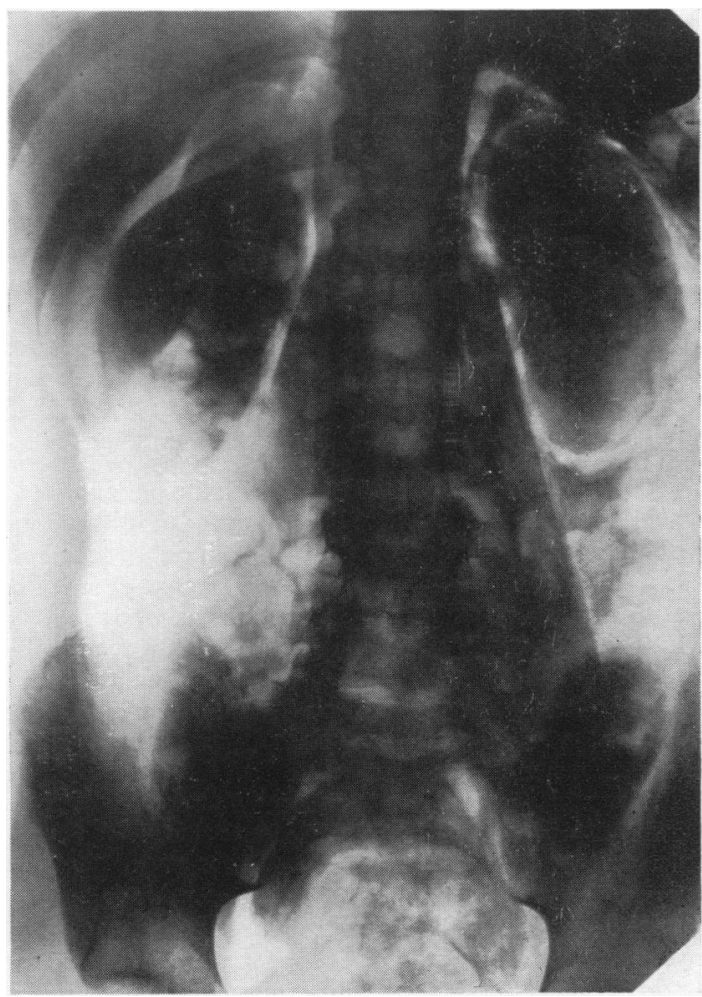

Fig. 3.-Extraperitoneal pneumogram.

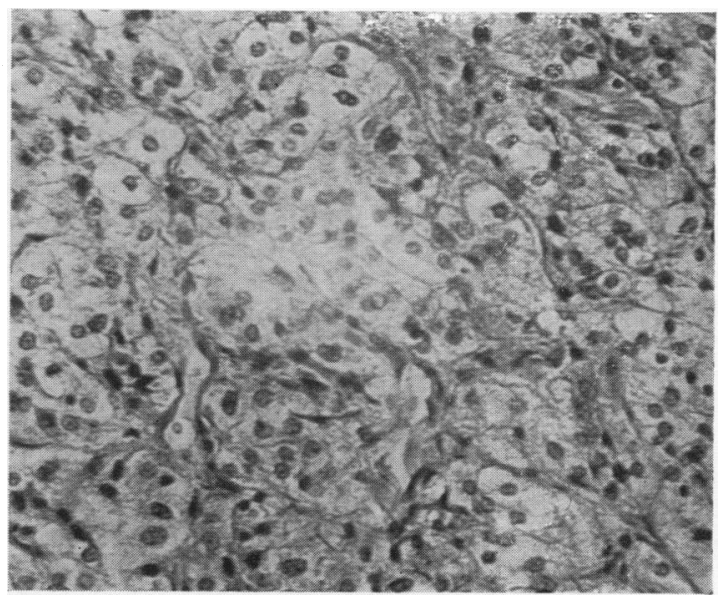

FIG. 4. - Section of tumour. $\times 400$.

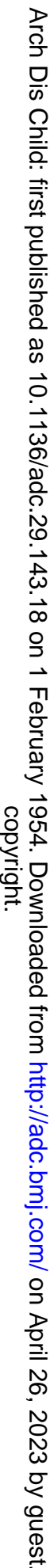

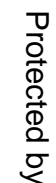


hour before, and blood pressure readings were taken at frequent intervals throughout the procedure. With the patient in the left lateral position, $400 \mathrm{ml}$. of air was injected; he was then placed in the right lateral position and a further $400 \mathrm{ml}$. injected. An x-ray picture taken immediately showed surgical emphysema to be limited to the pelvis. After the boy had walked about slowly for five minutes a further film showed the air to have reached the underside of the diaphragm and the kidneys and a tumour at the upper pole of the right kidney was clearly outlined. The left suprarenal shadow was normal (Fig. 3). During the whole of the procedure the boy's only complaint was of slight abdominal discomfort. His blood pressure, initially $180 / 150 \mathrm{~mm}$. $\mathrm{Hg}$, rose to $200 / 170$ then fell spontaneously to $150 / 110$.

Operation on March 2, 1953. - With the patient lying on his left side, the right kidney was approached through an oblique incision in the right loin. The incision crossed the last rib, the outer half of which was resected. A small hole accidentally made in the pleura was repaired. The kidney was exposed and then pulled downwards by a retractor held by the assistant; the tumour at its upper pole came into view. With a minimum of manipulation, the tumour was gently separated from the surrounding fatty tissue, which was very vascular. The line of demarcation was clear and apart from persistent oozing of blood from the fat, the removal of the tumour was easy. At the medial side of the tumour a large vein of the dimensions of a lead pencil passed to the inferior vena cava. This vessel was carefully divided between ligatures. Some yellow tissue seen in the bed of the tumour appeared to be normal suprarenal tissue. The wound was closed without drainage after complete haemostasis had been established. A chest radiograph taken at the conclusion of the operation showed no pneumothorax.

Anaesthesia and Management during Operation.The anaesthetic was given by Dr. E. S. M. Merry. After premedication with omnopon, gr. $\frac{1}{6}$, and scopolamine, gr. $\frac{1}{3} \delta$, anaesthesia was induced with intravenous thiopentone, $0.2 \mathrm{~g}$., and continued with nitrous oxide and oxygen. Tubarine, $8 \mathrm{mg}$., was then given intravenously and a cuffed endotracheal tube inserted. Throughout the operation nitrous oxide, oxygen and minimal amounts of ether were given.

It was planned to prevent the systolic blood pressure from rising above $200 \mathrm{~mm}$. by the use of benzodioxane intravenously; accordingly the first step was to begin an intravenous infusion with dextrose saline. In practice, fluctuations in the blood pressure occurred so rapidly, particularly during the first stage of anaesthesia, that isolated readings above this figure were obtained, the highest reading being $230 \mathrm{~mm}$. During the course of the operation benzodioxane was injected on eight occasions, a total of $54 \mathrm{mg}$. being given.

After the efferent vein had been clamped nor-adrenaline was infused at a rate of $6 \mu \mathrm{g}$. per minute. The blood pressure remained constant between 100 and 115 systolic and 65 and 80 diastolic, so that after two hours the rate of infusion was gradually reduced, the infusion being finally discontinued five hours after operation.
Pathology of the Tumour.-The tumour, brownish red and ovoid, measured 2 in. $\times 1 \frac{1}{2}$ in. $\times 1 \frac{1}{4}$ in. Microscopically it had the appearances of a typical phaeochromocytoma with no evidence of malignancy (Fig. 4).

Nor-adrenaline was isolated from the tumour.

Post-operative Course.-The boy's blood pressure has remained in the range of 105 to 125 systolic and 75 to 85 diastolic, he no longer sweats excessively, and he has had no headaches. During the two months since the operation he has gained $10 \frac{1}{4} \mathrm{lb}$., and has lost his anxious and drawn expression. The fundi still show star figures in the macular regions, but the discs themselves are normal.

\section{Discussion}

The symptoms associated with phaeochromocytoma may be paroxysmal at first and later sustained, or, sustained from the onset. Although this boy had no dramatic crises, his symptoms showed great variation in degree, but at no time was he symptom free. Similarly his blood pressure, while being persistently raised, showed a marked lability, not only from day to day but frequently from minute to minute. This variation in the blood pressure during the stage of persistent hypertension was a feature of the cases reported by Hubble (1951) and by Neill and Smith (1952).

The benzodioxane test was positive, supporting the clinical diagnosis. The great value of this test is now recognized, although negative results in proved cases of phaeochromocytoma and positive results in their absence have been described. Tulloh (1952), reported an example of a false negative test, and, reviewing previously reported similar cases, considered the factors which may have been responsible. False positive results appear to be even less frequent, but may occur in the presence of adrenal medullary hyperplasia (Taliaferro, Adams and Haag, 1949). One may conclude with Hubble that the benzodioxane test, although not completely reliable, 'has a degree of specificity unusual in most clinical or laboratory diagnostic tests'.

The demonstration of an increased urinary excretion of nor-adrenaline is the most convincing evidence of the presence of a phaeochromocytoma. In our patient $2,000 \mu \mathrm{g}$. was excreted in 24 hours, a level which is 100 times the average value. Dr. G. P. Burn (personal communication) pointed out that the nor-adrenaline urinary excretion has to be correlated with the clinical state of the patient and the blood pressure levels during the period over which the specimen is being collected. In patients with paroxysmal attacks the urinary nor-adrenaline level is likely to be significantly raised only during attacks and to be normal during the asymptomatic periods.

Retro-peritoneal pneumography was used to localize the tumour. This method of investigation, 
first introduced by Ruiz Rivas (1950), consists in the production of a retro-peritoneal emphysema by the injection of air into the pre-sacral areolar tissue. As this area is poorly vascularized the procedure appears to be devoid of the risk of air embolism, a disaster which has brought perirenal air insufflation into discredit. Steinbach, Lyon, Smith and Miller (1952) quote Ruiz Rivas as stating that L. P. Mosca has collected 1,500 cases of extra-peritoneal pneumography including 220 of his own without any fatal complications. Accurate pre-operative localization of the tumour is of great assistance in planning the operation, and in the case of our patient allowed an approach through the loin to be made instead of by the more difficult transperitoneal route. This latter route is advocated by Sprague, Kvale and Priestley (1953) on the grounds that pre-operative localization of the tumour is often impossible, and also because multiple and bilateral tumours may be present. While it is true that multiple tumours may be present, Mac Keith (1944) states that 'the common lesion is a benign adenoma of one adrenal body', and of 152 cases he reviewed, in all but 16 a single tumour was present. Retro-peritoneal pneumography in the case of our patient gave the added and valuable information that the contralateral supra-renal appeared normal.

The chief hazard of operative procedures of any kind, and particularly of those which involve manipulation of the tumour, is that hypertensive crises may occur as a result of the discharge of noradrenaline into the circulation. Such crises are liable to be followed by a state of severe and often fatal peripheral circulatory collapse. It is important therefore that at operation the tumour should be disturbed as little as possible until the efferent vein has been ligated, and also that an adrenolytic agent should be held ready for immediate injection. For this purpose benzodioxane, which has a transient action, is to be preferred to dibenamine, the effects of which are similar but persist for two or three days. If dibenamine were to be used, it would, by its more prolonged action, prevent the use of nor-adrenaline should it be required to correct a post-operative fall in blood pressure.

\section{Summary}

A case of phaeochromocytoma in a boy aged 10 years is described. The benzodioxane test was positive and the urinary excretion of nor-adrenaline was markedly raised.

Retro-peritoneal pneumography demonstrated the tumour, which was successfully removed.

We are grateful to Dr. G. P. Burn for his advice and for carrying out the nor-adrenaline estimation, to Dr. McCullagh Wilson for his report on the pathology of the tumour, to Mr. Partridge for the photographs. Dr. Joyce, the paediatric house physician, rendered invaluable assistance.

\section{REFERENCES}

Blackwood, J. (1951). Brit. J. Surg., 39, 111.

Euler, U. S. von (1951). Brit. med. J., 1, 105

Goldenberg, M., Snyder, C. H. and Aranow, H., Jr. (1947). J. Amer. med. Ass., 135, 971 .

Hubble, D. (195i). Archives of Disease in Childhood, 26, 340.

Mac Keith, R. (1944). Brit. Heart J., 6, 1.

Neill, C. A. and Smith, G. (1952). Archives of Disease in Childhood, 27, 286.

Ruiz Rivas, M. (1950). Amer. J. Roentgenol., 64, 723.

Sprague, R. G., Kvale, W. F. and Priestley, J. T. (1953). J. Amer. med. Ass., 151, 629.

Steinbach, H. L., Lyon, R. P., Smith, D. R. and Miller, E. R. (1952). Radiology, 59, 167.

Taliaferro, I., Adams, R. A. and Haag, H. B. (1949).

Tulloh, H. P. (1952). Brit. med. J., 1, 531 . 